\title{
BMJ Open Effects of electrical muscle stimulation in frail elderly patients during haemodialysis (DIAL): rationale and protocol for a crossover randomised controlled trial
}

\author{
Yuta Suzuki, ${ }^{\oplus 1}$ Kentaro Kamiya, ${ }^{2}$ Shinya Tanaka, ${ }^{2}$ Keika Hoshi, ${ }^{3}$ \\ Takaaki Watanabe, ${ }^{1}$ Manae Harada, ${ }^{1}$ Ryota Matsuzawa, ${ }^{4}$ Takahiro Shimoda, ${ }^{1}$ \\ Shohei Yamamoto, ${ }^{1}$ Yusuke Matsunaga, ${ }^{5}$ Kei Yoneki, ${ }^{1}$ Atsushi Yoshida, ${ }^{6}$ \\ Atsuhiko Matsunaga ${ }^{1}$
}

To cite: Suzuki Y, Kamiya K, Tanaka S, et al. Effects of electrical muscle stimulation in frail elderly patients during haemodialysis (DIAL): rationale and protocol for a crossover randomised controlled trial. BMJ Open 2019;9:e025389. doi:10.1136/ bmjopen-2018-025389

- Prepublication history for this paper is available online. To view these files, please visit the journal online (http://dx.doi. org/10.1136/bmjopen-2018025389).

Received 12 July 2018 Revised 30 January 2019 Accepted 13 February 2019
Check for updates

(C) Author(s) (or their employer(s)) 2019. Re-use permitted under CC BY-NC. No commercial re-use. See rights and permissions. Published by BMJ.

For numbered affiliations see end of article.

Correspondence to

Dr Kentaro Kamiya;

k-kamiya@kitasato-u.ac.jp

\section{ABSTRACT}

Introduction The phenomenon of population ageing is accompanied by increases in the number of elderly haemodialysis patients worldwide. The incidence of frailty is high in the haemodialysis population and is associated with poor clinical outcome. Although several interventions have been developed for use in general haemodialysis patients, the efficacy of such rehabilitation programmes in frail elderly patients on haemodialysis has not been elucidated. Here, we examined whether electrical muscle stimulation (EMS) would show beneficial effects in frail elderly patients on haemodialysis.

Methods and analysis This is a randomised, twoperiod, controlled crossover trial, which will enrol 20 patients. Haemodialysis patients aged $\geq 65$ years and defined as frail (ie, Short Physical Performance Battery score 4-9), will be randomly assigned to either group 1 (EMS intervention beginning in treatment period $\mathrm{I}$, followed by reallocation as controls in treatment period II after a 5-week washout period) or group 2 (opposite schedule) in a 1:1 ratio. The two intervention periods will last 5 weeks each with an intervening washout period of 5 weeks. In the EMS intervention group, the treatment will be applied to the skeletal muscle of the entire lower extremity for 5 weeks, three times/week for 30-40 min during haemodialysis. The primary outcome of this study is the change in quadriceps isometric strength after the interventions. The secondary outcomes are the changes in physical function, physical activity, difficulty in activities of daily living, body composition, cognitive function, depressive symptoms, quality of life, blood test results and the clinical safety and feasibility of EMS therapy. Ethics and dissemination This study has been approved by the institutional review board/ethics committee of Kitasato University Allied Health Sciences. This study will be reported in peer reviewed publications and at conference presentations. Trial registration number UMIN000032501.

\section{Strengths and limitations of this study}

- This is the first randomised controlled trial of a rehabilitation programme during dialysis in elderly haemodialysis patients.

- This is a single-blinded study and will enrol 20 patients

- The main objective is to determine the clinical efficacy of electrical muscle stimulation in frail elderly haemodialysis patients.

- The primary outcome is the change in quadriceps isometric strength after intervention.

- This study will provide the first evidence of the efficacy of a rehabilitation programme in elderly haemodialysis patients.

\section{INTRODUCTION}

Frailty in the elderly is defined as the cumulative deterioration of multiple physiological systems, which leads to impaired homeostasis and reduced capacity to withstand stress. ${ }^{1-4}$ Frailty in the elderly is a global public health problem, which is a predictor of mortality and hospitalisation risk, regardless of comorbidities and disability status. ${ }^{56}$

Engagement in individually tailored appropriately structured exercise training has been shown to be beneficial for haemodialysis patients. ${ }^{7}$ However, frail elderly haemodialysis patients encounter several barriers in exercising, including time restriction associated with continuous dialysis treatment, limited physical capacity and low adherence to conventional exercise programmes. ${ }^{8-10}$ Therefore, it is necessary to develop effective rehabilitation programmes for such patients.

Electrical muscle stimulation (EMS) is a new method for rehabilitation that can be 


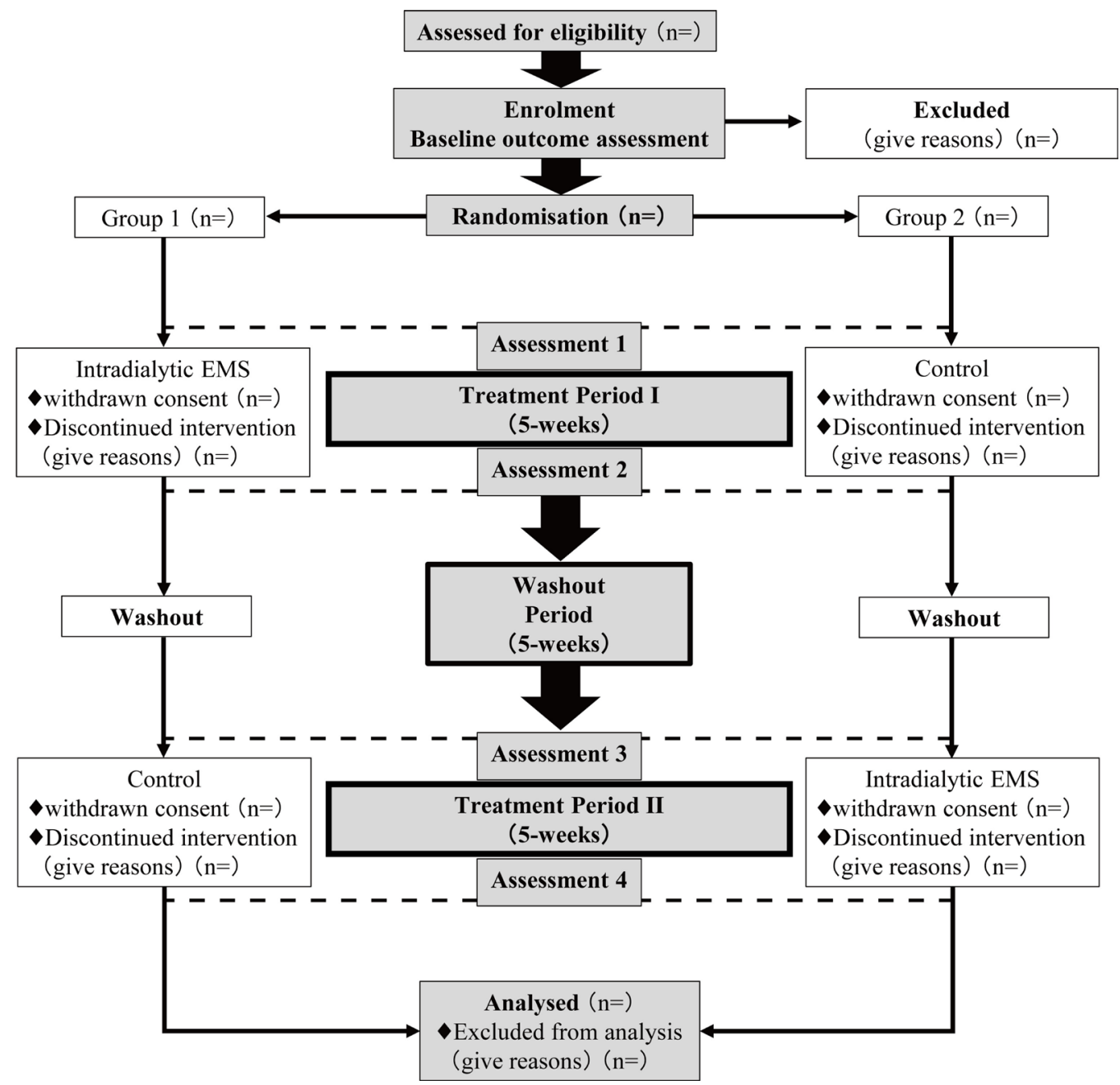

Figure 1 Study flow diagram. EMS, electrical muscle stimulation.

used by patients while lying down; this method has no time restriction, requires no volitional effort and places no haemodynamic stress on the patient. ${ }^{11}$ Recent studies reported that intradialytic EMS can improve muscle strength, exercise capacity and health-related quality of life (QOL) in haemodialysis patients without associated adverse events. ${ }^{12-17}$ However, little is known about whether EMS improves physical function in frail haemodialysis patients.

This study (designated as the DIAL trial, for 'DIALysis') will evaluate whether EMS during dialysis may be beneficial to reduce physical function impairment in frail elderly haemodialysis patients.

\section{METHODS AND ANALYSIS}

\section{Trial design}

This is a randomised, prospective, two-period, singleblinded, controlled crossover trial. Permuted block randomisation will be being performed with a 1:1 allocation. Figure 1 shows a flow chart of the study, designed according to the Consolidated Standards of Reporting Trials Extended Non-Drug guidelines ${ }^{18}$ and the Standard
Protocol Items: Recommendations for Interventional Trials 2013 guidelines for clinical trial protocols. ${ }^{19}$

\section{Objectives}

This study will examine the clinical efficacy of EMS during haemodialysis to improve physical function in frail elderly haemodialysis patients. In addition, this study will examine additional health-related benefits of EMS and evaluate the clinical safety and feasibility of using EMS in frail elderly haemodialysis patients.

\section{Study setting}

This single-centre study will be organised and administered by the Graduate School of Medical Sciences, Kitasato University, Sagamihara, Kanagawa, Japan. This study will screen approximately $60 \%$ patients in the facility.

\section{Eligibility criteria}

The inclusion and exclusion criteria for the study are listed in box 1 . The criteria for inclusion in the study are clinically stable elderly patients aged $\geq 65$ years with chronic kidney disease undergoing maintenance haemodialysis therapy three times per week with frailty as defined by mobility limitations according to the Short Physical Performance 


\section{Box 1 Inclusion or exclusion criteria}

\section{Inclusion criteria}

- Outpatients with chronic kidney disease undergoing maintenance haemodialysis therapy.

- Aged 65 years or more.

- Frail patients (Short Physical Performance Battery score 4-9).

\section{Exclusion criteria}

- Cognitive dysfunction.

- Significant myocardial ischaemia during low-intensity exercise.

Resting heart rate $>120 / \mathrm{min}$.

- Recent hospitalisation (<3 month).

- Resting blood pressure $>180 \mathrm{~mm} \mathrm{Hg}$.

- Ongoing orthopnoea.

- Patients with inadequate oxygenation.

- Patients with uncontrolled diabetes.

- Recent embolism.

- Recent cardiovascular events.

- Recent bone fracture (<1 year).

- Skin abnormality at the adaptive site.

- Severe iron deficiency.

- Patients with cardiac pacemakers or implantable cardioverter defibrillator.
Battery (SPPB, score 4-9). ${ }^{20}{ }^{21}$ Cognitive dysfunction will be examined at baseline by Mini-Cog assessment. ${ }^{22}{ }^{23}$ Baseline Mini Nutritional Assessment-Short Form will be performed to screen for malnutrition. ${ }^{24}{ }^{25}$ All patients will provide written informed consent prior to inclusion in the study (table 1).

\section{Randomisation and blinding}

Enrolment will be implemented at single centre in Japan. Permuted block randomisation will be used, with a computerised random allocation sequence generated using Stata (Stata Corp). To ensure concealment, the block sizes will be not disclosed. Patients will be allocated to the groups by the researcher in charge of this process, with the patients, research investigators, outcome assessors and data analysts blinded to the allocations. Allocation to one of the experimental groups will be achieved by assigning each patient a random number in a sealed opaque envelope. Group allocation will be concealed by ensuring that the results are not be disclosed until after baseline outcome assessment when the patient has been recruited into the trial. Patients, research investigators and outcome assessors will be unblinded to the allocation

Table 1 Schematic diagram of study schedule

\section{Study period}

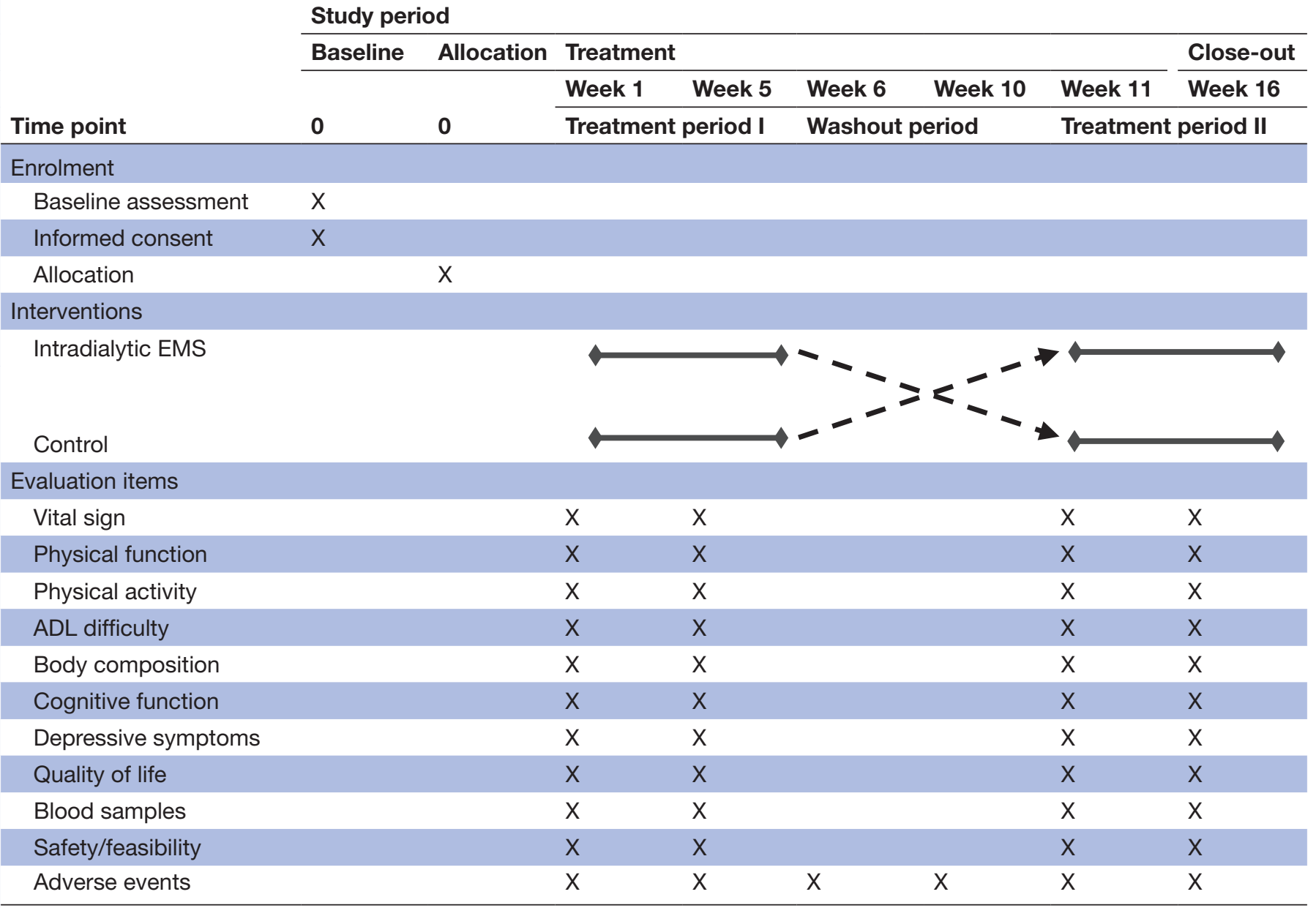

$A D L$, activity of daily living; EMS, electrical muscle stimulation. 
results after baseline outcome assessment. However, the data analysts will be blinded to the allocation. The research investigators will record outcome measurements on separate datasheets, enabling standard care without knowledge of the allocation results by the haemodialysis care providers and other non-research staff. To ensure that statistical analyses are performed in a blinded manner, the data analysts will have no knowledge of the codes for assigned groups until after the data have been analysed.

\section{Intervention}

The study population will be randomly assigned to either group 1 or group 2 in a 1:1 ratio. The study will include two intervention periods, designated as treatment period I and treatment period II, each of which will last for 5 weeks with an intervening 5-week washout period (figure 1). Group 1 will receive the EMS intervention in treatment period I, and then be reallocated to control in treatment period II after the 5-week washout period. Group 2 will receive the control in treatment period I, and then be reallocated to the EMS intervention in treatment period II after the 5-week washout period. A previous study indicated that a 5-week washout period would be sufficient to eliminate carry-over effects. ${ }^{26}$ Symptoms and vital signs, including heart rate, blood pressure and dialysis conditions, will be recorded during the EMS interventions (table 1). To confirm the safety of the interventions, the record sheets for each patient will be reviewed to identify haemodynamic compromise, cardiovascular decompensation and musculoskeletal injuries. For patients leaving the clinic before the end of the treatment period, we will count the number of times they received EMS interventions.

\section{EMS protocol}

EMS will be performed on each leg using belt electrode skeletal muscle electrical stimulation (area per leg $50 \times 5.5 \mathrm{~cm}$ and $36 \times 5.5 \mathrm{~cm}$ ) (General Therapeutic Electrical Stimulator; Homer Ion, Tokyo, Japan). ${ }^{27} 28$ Belt electrode skeletal muscle electrical stimulation will be applied to the muscles of the entire lower extremity, including the gluteal muscle, quadriceps femoris, hamstrings, tibialis anterior and triceps surae muscles. Five silicon-rubber electrode bands will be applied to the patients at the waist and on distal parts of the bilateral thighs and ankles. The anodes will be placed on the distal thigh with the cathodes on the waist and ankle. The stimulator current waveform will have a frequency of $20 \mathrm{~Hz}$, pulse width of $250 \mu$ s and duty cycle of $5 \mathrm{~s}$ with a pause for $2 \mathrm{~s}$ to produce cocontractions in the muscle groups of the lower extremities. ${ }^{27} 29$ All lower extremity muscles will be stimulated simultaneously. The output intensity will be individually tailored to the maximum tolerable value without discomfort or pain to induce visible muscle contractions. Patients will be placed in the supine position with a pillow under the knees. EMS will be performed for 30-40 min per day, 3 days per week for 5 weeks between the first and second hours of dialysis. The Borg rating of perceived exertion (RPE) scale and numerical rating scale of pain (NRS) will be recorded every 10 min during EMS. The current intensity will be set to the maximum intensity at the beginning of an each EMS session by the investigator. Thereafter, the investigator will adjust the current intensity every 10 min to maintain the maximum tolerable intensity while simultaneously recording the RPE scale and NRS scores. The electrical current intensity and time will be recorded for each EMS session. If any patients refuse EMS therapy, we will assess the reason for refusal and evaluate the persistence rate of the EMS intervention.

\section{Control protocol}

Patients will not receive EMS interventions in the control period. Outcomes will only be assessed before and after 5 weeks of treatment period I or II.

\section{Outcomes}

As it is a good predictor of exercise capacity, activity of daily living (ADL) performance and mortality, the change in quadriceps isometric strength (QIS) after in comparison to before the intervention (ie, from baseline to 5 weeks and from 10 weeks to 15 weeks) was selected as the primary outcome of this study. ${ }^{3031} \mathrm{~A}$ handheld dynamometer ( $\mu$-Tas; ANIMA, Tokyo, Japan) will be used to assess maximal QIS with the patient on a bed with the knee joint in $90^{\circ}$ flexion and hip joint in $90^{\circ}$ flexion. Maximal isometric voluntary contractions of the quadriceps for $5 \mathrm{~s}$ will be collected three times for both legs. The right and left quadriceps will be tested consecutively, and the highest peak strength values on the right and left sides will be averaged and expressed as both absolute value (kgf) and relative to dry weight (\%). ${ }^{32}$ The secondary outcomes in the trial will be the changes in physical function, physical activity, difficulties in ADL, body composition, cognitive function, depressive symptoms, QOL, differences in blood test results between before and after the interventions and the clinical safety and feasibility of EMS therapy during dialysis.

Handgrip strength $(\mathrm{kg})$, SPPB score (points), usual gait speed $(\mathrm{m} / \mathrm{s})$, and maximum gait speed $(\mathrm{m} / \mathrm{s})$ will be measured as determinants of physical function.

Physical activity will be measured using an accelerometer worn around the waist (Lifecorder; Suzuken, Nagoya, Japan) continuously for 1 week before and after each of treatment periods I and II. The average number of steps per day will be analysed.

Difficulties in ADL will be determined using a questionnaire consisting of 12 items based on self-rated mobility difficulty developed for patients undergoing haemodialysis therapy. ${ }^{31}$ The difficulty in ADL score will be defined as the total score from the 12 items in the questionnaire and will range from 12 to 60 points.

In the study, body composition will be determined using InBody S10 (InBody Japan, Tokyo, Japan) with operating frequencies of 1, 5, 50, 250, 500 and $1000 \mathrm{kHz}$. The body composition of the trunk and each limb will be measured 
separately using sensors attached to each of the four segments of the body (right arm, left arm, right leg, left leg). Measurements will be taken with the patient in the sitting position before haemodialysis. Body composition will be determined based on skeletal muscle mass $(\mathrm{kg})$, fat mass $(\mathrm{kg})$, lean body mass $(\mathrm{kg})$, body fat rate $(\%)$, skeletal muscle index $\left(\mathrm{kg} / \mathrm{m}^{2}\right)$ and extracellular water/total body water ratio.

The Digit Symbol Substitution Test, with the number of correct number-symbol matches in 90 sec taken as the score (points), will be used to assess cognitive function. ${ }^{33}$

The short version of the Center for Epidemiological Studies Depression Screening Index, which is a self-reported questionnaire, will be used to determine depressive symptoms in the patients. ${ }^{34-36}$

QOL will be measured using the medical outcome study (MOS) 36-Item Short-Form Health Survey physical functioning scale (SF-36 PF). ${ }^{37} 38$ Although SF-36 PF provides information related to self-rated health over eight domains of physical and mental health, this study will focus only on physical function. ${ }^{39}$

Physicians outside the research team and blinded to the allocation results will collect blood samples from the patients at baseline and after 5, 10 and 15 weeks of the therapeutic interventions. All blood samples will be drawn before dialysis at the beginning of the week. Serum creatinine $(\mathrm{mg} / \mathrm{dL})$, urea nitrogen $(\mathrm{mg} / \mathrm{dL})$, albumin $(\mathrm{g} / \mathrm{dL})$, haemoglobin $(\mathrm{g} / \mathrm{dL})$, calcium $(\mathrm{mg} / \mathrm{dL})$, potassium $(\mathrm{mEq} / \mathrm{L})$, low-density lipoprotein (LDL) cholesterol $(\mathrm{mg} / \mathrm{dL})$ and high-density lipoprotein (HDL) cholesterol $(\mathrm{mg} / \mathrm{dL})$ will be measured as biochemical parameters.

Adverse events occurring during the study period will be assessed as secondary outcomes, and the feasibility of EMS therapy will be determined by the Borg RPE scale (points), NRS (points), current intensities during EMS $(\mathrm{mA})$ and maximum current intensities in individual EMS sessions $(\mathrm{mA})$. Here, compliance with EMS therapy is defined as the percentage of EMS intervention attempted by the patients (\%) (table 2).

\section{Statistical analysis and sample size}

Intention-to-treat analyses will be performed. Changes in outcome measures will be expressed as means \pm SD deviation or medians (25th percentile-75th percentile). The primary outcome will be examined by paired t-test or Wilcoxon's signed-rank test as appropriate. The secondary outcomes will be analysed by paired t-test or Wilcoxon's signed-rank test for continuous variables. For all except interaction analysis, a two-tailed $p$ value $<0.05$ will be taken to indicate statistical significance. In addition, combined data from Treatment Period I and Treatment Period II will be compared.

The sample size has been calculated using PS Power and Sample Size Calculation software (Vanderbilt University, Nashville, Tennessee, USA) on the primary outcome measure (ie, change in QIS). Based on the results of previous studies, ${ }^{13}$ we plan to study continuous response variables from paired subjects. Previous data indicated that the change in QIS, the outcome between two interventions, is $44 \mathrm{~N}(4.49 \mathrm{kgf})$ with $\mathrm{SD}$ of $53 \mathrm{~N}$ (5.41 kgf). Therefore, 15 patients will be needed for a power of $85 \%$ and an alpha value of $5 \%$. Assuming $25 \%$ loss to follow-up, it will be necessary to enrol 20 patients in this study. The 20 patients will be randomised based on previous findings regarding similar patients at our institute.

\section{Patient and public involvement}

Patient and public involvement will not be performed in development of the research question, outcome and study design; the recruitment to and conduct of this trial. We will disseminate the study results to the study participants after publishing in a peer-reviewed journal. Although the burden of the intervention will not be assessed by study participants, it will not be a heavy burden for study participants because EMS intervention will be performed during dialysis.

\section{ETHICS AND DISSEMINATION}

The trial was registered at the University Hospital Medical Information Network Clinical Trials Registry prior to patient recruitment. All patients will receive a thorough explanation of the study and only those patients that provide written consent will be included.

The start date of the study was May 2018. The study results will be disseminated through peer-reviewed manuscripts and international conference presentations.

\section{DISCUSSION}

Disease management in frail elderly haemodialysis patients is a matter of increasing concern due to the growing size of this population. There have been no previous reports of rehabilitation programmes with significant beneficial effects in these patients. This study was designed to examine the efficacy of a new rehabilitation programme using of EMS therapy in frail elderly haemodialysis patients.

The prevalence of frailty in haemodialysis patients is higher than that in their community-dwelling counterparts. ${ }^{40}$ This is due to the rapid increase in number of elderly haemodialysis patients, ${ }^{41}{ }^{42}$ accelerated ageing due to kidney disease $\mathrm{e}^{434}$ and the synergistic effects of ageing and kidney disease. ${ }^{42}$ Thus, frailty in haemodialysis patients is known as a syndrome resulting from multiple physiological changes.

There have been a number of studies regarding the adverse events of frailty in patients receiving haemodialysis. ${ }^{45-48}$ It is important to take physical impairments into account when planning rehabilitation programmes for these patients. A new programme suitable for use in frail haemodialysis patients may reduce the rates of poor outcomes, including hospitalisation, falls and death in this population. 


\begin{tabular}{|c|c|}
\hline Outcome measure & Information \\
\hline Primary & - Change in QIS (kgf and \%). \\
\hline Physical function & $\begin{array}{l}\text { Change in the handgrip strength }(\mathrm{kg}) \text {. } \\
\text { Change in the SPPB score (points). } \\
\text { Change in the usual gait speed }(\mathrm{m} / \mathrm{s}) \text {. } \\
\text { Change in the maximum gait speed }(\mathrm{m} / \mathrm{s}) \text {. }\end{array}$ \\
\hline Physical activity & Change in the number of steps of the day (steps/day). \\
\hline ADL difficulty & $\begin{array}{l}\text { Change in the questionnaire developed for patients undergoing haemodialysis } \\
\text { therapy (points). }\end{array}$ \\
\hline Body composition & $\begin{array}{l}\text { Change in the skeletal muscle mass }(\mathrm{kg}) \text {. } \\
\text { Change in the fat mass }(\mathrm{kg}) \text {. } \\
\text { Change in the lean body mass }(\mathrm{kg}) . \\
\text { Change in the body fat rate }(\%) . \\
\text { Change in the skeletal muscle index }\left(\mathrm{kg} / \mathrm{m}^{2}\right) . \\
\text { Extracellular water/total body water ratio. }\end{array}$ \\
\hline Cognitive function & Change in the DSST score (points). \\
\hline Depressive symptoms & Change in the 10-item CES-D score (points). \\
\hline QOL & Change in the SF-36 PF score (points). \\
\hline Blood samples & $\begin{array}{l}\text { Change in the serum creatinine levels }(\mathrm{mg} / \mathrm{dL}) \text {. } \\
\text { Change in the urea nitrogen levels }(\mathrm{mg} / \mathrm{dL}) \text {. } \\
\text { Change in the serum albumin }(\mathrm{g} / \mathrm{dL}) . \\
\text { Change in the haemoglobin levels }(\mathrm{g} / \mathrm{dL}) \text {. } \\
\text { Change in the calcium levels (mg/dL). } \\
\text { Change in the potassium levels (mEq/L). } \\
\text { Change in the LDL cholesterol levels (mg/dL). } \\
\text { Change in the HDL cholesterol levels }(\mathrm{mg} / \mathrm{dL}) \text {. }\end{array}$ \\
\hline
\end{tabular}

ADL, activity of daily living; CES-D, the short versions of the Center for Epidemiological Studies Depression Screening Index; DSST, the Digit Symbol Substitution Test; EMS, electrical muscle stimulation; HDL, high-density lipoprotein; LDL, low-density lipoprotein; NRS, Numerical Rating Scale; QIS, quadriceps isometric strength; QOL, quality of life; RPE, rating of perceived exertion; SF-36 PF, medical outcome study 36-item Short-Form Health Survey Physical Functioning Scale; SPPB, short physical performance battery.

Exercise training is an effective intervention that can ameliorate the marked physiological and functional deterioration seen in frail elderly patients. ${ }^{49}$ However, there is insufficient evidence regarding the effectiveness of exercise training in elderly haemodialysis patients. ${ }^{50-52}$ Furthermore, exercise therapy is difficult for frail elderly haemodialysis patients due to functional decline, time restriction and low rates of adherence to the programme. Exercise therapy is recommended for maintenance of physical function in patients (especially frail elderly patients) on haemodialysis. ${ }^{45}$ Rehabilitation programmes using of EMS were shown to improve physical function, exercise capacity and other health-related outcomes with reduced levels of haemodynamic risk in haemodialysis patients. We postulated that the application of EMS would be effective as a rehabilitation programme in frail elderly haemodialysis patients. Improvement of the condition of the lower extremities muscles is essential for mobility, exercise capacity, daily physical activity and avoiding other factors associated with poor prognosis. ${ }^{5354}$ Therefore, the primary outcome of this trial is lower extremity muscle strength as this parameter is markedly impaired in frail elderly haemodialysis patients.

This study had some limitations. First, the patient population is relatively small, and all subjects will be Japanese at single centre. Second, the outcome assessors cannot be blinded to the allocation results, which may result in bias favouring EMS therapy.

Given these limitations, this is the first randomised controlled trial of a rehabilitation programme during dialysis in elderly haemodialysis patients. As EMS can be applied during dialysis, which is the time when the 
greatest degree of reduction in muscle function occurs, this study may facilitate the development of novel rehabilitation programmes that will be beneficial in frail elderly dialysis patients.

\section{CONCLUSION}

The results of this crossover randomised controlled trial examining the effects of EMS therapy in frail elderly haemodialysis patients will facilitate the development of effective rehabilitation programmes for this patient population.

\section{Author affiliations \\ ${ }^{1}$ Rehabilitation Sciences, Kitasato University Graduate School of Medical Sciences, Sagamihara, Japan \\ ${ }^{2}$ Rehabilitation, Kitasato University School of Allied Health Sciences, Sagamihara, Japan \\ ${ }^{3}$ Department of Hygiene, Kitasato University School of Medicine, Kanagawa, Japan \\ ${ }^{4}$ Department of Rehabilitation, Kitasato University Hospital, Sagamihara, Japan \\ ${ }^{5}$ Sleep Medicine, Kitasato University Graduate School of Medical Sciences, \\ Sagamihara, Japan \\ ${ }^{6}$ Haemodialysis Center, Sagami Circulatory Organ Clinic, Sagahihara, Japan}

Contributors YS, KK, ST, KH, TW, MH, RM, TS, SY, YM, KY, AY, and AM codesigned this study. YS, KK, ST and KH are responsible for the coordination statistical analysis plan. YS, KK, ST, KH and TS wrote this manuscript. All authors contributed to the revision of this manuscript.

Funding This work was supported by JSPS KAKENHI Grant Number 26350631. Competing interests None declared.

Patient consent for publication Not required

Ethics approval The study protocol has been approved by the institutional review board/ethics committee of Kitasato University Allied Health Sciences, and will be conducted in accordance with the principles of the Declaration of Helsinki.

Provenance and peer review Not commissioned; externally peer reviewed.

Open access This is an open access article distributed in accordance with the Creative Commons Attribution Non Commercial (CC BY-NC 4.0) license, which permits others to distribute, remix, adapt, build upon this work non-commercially, and license their derivative works on different terms, provided the original work is properly cited, appropriate credit is given, any changes made indicated, and the use is non-commercial. See: http://creativecommons.org/licenses/by-nc/4.0/.

\section{REFERENCES}

1. Fried LP, Ferrucci L, Darer J, et al. Untangling the concepts of disability, frailty, and comorbidity: implications for improved targeting and care. J Gerontol A Biol Sci Med Sci 2004;59:M255-63.

2. Fried LP, Tangen CM, Walston J, et al. Frailty in older adults: evidence for a phenotype. J Gerontol A Biol Sci Med Sci 2001;56:M146-56.

3. Morley JE, Vellas B, van Kan GA, et al. Frailty consensus: a call to action. J Am Med Dir Assoc 2013;14:392-7.

4. Morley JE. Frailty and Sarcopenia: The New Geriatric Giants. Rev Invest Clin 2016;68:59-67.

5. Afilalo J, Alexander KP, Mack MJ, et al. Frailty assessment in the cardiovascular care of older adults. J Am Coll Cardio 2014;63:747-62.

6. Singh M, Stewart R, White $\mathrm{H}$. Importance of frailty in patients with cardiovascular disease. Eur Heart J 2014;35:1726-31.

7. Cheema BS, Singh MA. Exercise training in patients receiving maintenance hemodialysis: a systematic review of clinical trials. Am J Nephrol 2005;25:352-64.

8. Nied RJ, Franklin B. Promoting and prescribing exercise for the elderly. Am Fam Physician 2002;65:419-26.

9. Painter P. Physical functioning in end-stage renal disease patients: update 2005. Hemodial Int 2005;9:218-35.

10. Johansen KL. Resistance exercise in the hemodialysis population who should do the heavy lifting? Am J Nephrol 2016;44:29-31.
11. Tanaka S, Masuda T, Kamiya K, et al. A single session of neuromuscular electrical stimulation enhances vascular endothelial function and peripheral blood circulation in patients with acute myocardial infarction. Int Heart J 2016;57:676-81.

12. Brüggemann AK, Mello CL, Dal Pont T, et al. Effects of neuromuscular electrical stimulation during hemodialysis on peripheral muscle strength and exercise capacity: a randomized clinical trial. Arch Phys Med Rehabil 2017;98:822-31.

13. Dobsak $P$, Homolka P, Svojanovsky J, et al. Intra-dialytic electrostimulation of leg extensors may improve exercise tolerance and quality of life in hemodialyzed patients. Artif Organs 2012;36:71-8.

14. Schardong J, Dipp T, Bozzeto CB, et al. Effects of Intradialytic Neuromuscular Electrical Stimulation on Strength and Muscle Architecture in Patients With Chronic Kidney Failure: Randomized Clinical Trial. Artif Organs 2017;41:1049-58.

15. Roxo RS, Xavier VB, Miorin LA, et al. Impact of neuromuscular electrical stimulation on functional capacity of patients with chronic kidney disease on hemodialysis. J Bras Nefrol 2016;38:344-50.

16. Simó VE, Jiménez AJ, Oliveira JC, et al. Efficacy of neuromuscular electrostimulation intervention to improve physical function in haemodialysis patients. Int Urol Nephrol 2015;47:1709-17.

17. Esteve V, Carneiro J, Moreno F, et al. The effect of neuromuscular electrical stimulation on muscle strength, functional capacity and body composition in haemodialysis patients. Nefrologia 2017;37:68-77.

18. Boutron I, Moher D, Altman DG, et al. Methods and processes of the CONSORT Group: example of an extension for trials assessing nonpharmacologic treatments. Ann Intern Med 2008;148:W-60-6.

19. Chan AW, Tetzlaff JM, Altman DG, et al. SPIRIT 2013 Statement: defining standard protocol items for clinical trials. Rev Panam Salud Publica 2015;38:506-14.

20. Guralnik JM, Ferrucci L, Pieper CF, et al. Lower extremity function and subsequent disability: consistency across studies, predictive models, and value of gait speed alone compared with the short physical performance battery. J Gerontol A Biol Sci Med Sci 2000;55:M221-31.

21. Guralnik JM, Ferrucci L, Simonsick EM, et al. Lower-extremity function in persons over the age of 70 years as a predictor of subsequent disability. N Engl J Med 1995;332:556-62.

22. Borson S, Scanlan JM, Chen P, et al. The Mini-Cog as a screen for dementia: validation in a population-based sample. J Am Geriatr Soc 2003;51:1451-4.

23. Borson S, Scanlan JM, Watanabe J, et al. Simplifying detection of cognitive impairment: comparison of the Mini-Cog and MiniMental State Examination in a multiethnic sample. J Am Geriatr Soc 2005;53:871-4.

24. Cereda E. Mini nutritional assessment. Curr Opin Clin Nutr Metab Care 2012;15:29-41.

25. Kaiser MJ, Bauer JM, Ramsch C, et al. Validation of the Mini Nutritional Assessment short-form (MNA-SF): a practical tool for identification of nutritional status. J Nutr Health Aging 2009;13:782-8

26. Toussaint ND, Polkinghorne KR, Kerr PG. Impact of intradialytic exercise on arterial compliance and B-type natriuretic peptide levels in hemodialysis patients. Hemodial Int 2008;12:254-63.

27. Numata $H$, Nakase J, Inaki A, et al. Effects of the belt electrode skeletal muscle electrical stimulation system on lower extremity skeletal muscle activity: Evaluation using positron emission tomography. J Orthop Sci 2016;21:53-6.

28. Miyamoto $T$, Kamada $H$, Tamaki $A$, et al. Low-intensity electrical muscle stimulation induces significant increases in muscle strength and cardiorespiratory fitness. Eur J Sport Sci 2016;16:1104-10.

29. Moritani T, Muro M, Kijima A. Electromechanical changes during electrically induced and maximal voluntary contractions: electrophysiologic responses of different muscle fiber types during stimulated contractions. Exp Neurol 1985;88:471-83.

30. Matsuzawa R, Matsunaga A, Wang G, et al. Relationship between lower extremity muscle strength and all-cause mortality in Japanese patients undergoing dialysis. Phys Ther 2014;94:947-56.

31. Watanabe T, Kutsuna T, Yoneki K, et al. Determinants of difficulty in activities of daily living in ambulatory patients undergoing hemodialysis. Renal Replacement Therapy 2018;4:8.

32. Bohannon RW. Reference values for extremity muscle strength obtained by hand-held dynamometry from adults aged 20 to 79 years. Arch Phys Med Rehabil 1997;78:26-32.

33. Salthouse TA. What do adult age differences in the digit symbol substitution test reflect? J Gerontol 1992;47:P121-8.

34. Andresen EM, Malmgren JA, Carter WB, et al. Screening for depression in well older adults: evaluation of a short form of the 
CES-D (Center for Epidemiologic Studies Depression Scale). Am J Prev Med 1994;10:77-84.

35. Irwin M, Artin KH, Oxman MN. Screening for depression in the older adult: criterion validity of the 10-item Center for Epidemiological Studies Depression Scale (CES-D). Arch Intern Med 1999;159:1701-4.

36. Lopes AA, Albert JM, Young EW, et al. Screening for depression in hemodialysis patients: associations with diagnosis, treatment, and outcomes in the DOPPS. Kidney Int 2004;66:2047-53.

37. Stewart AL, Hays RD, Ware JE. The MOS short-form general health survey. Reliability and validity in a patient population. Med Care 1988;26:724-35.

38. Green J, Fukuhara S, Shinzato T, et al. Translation, cultural adaptation, and initial reliability and multitrait testing of the Kidney Disease Quality of Life instrument for use in Japan. Qual Life Res 2001;10:93-100.

39. Stretton CM, Latham NK, Carter KN, et al. Determinants of physical health in frail older people: the importance of self-efficacy. Clin Rehabil 2006;20:357-66.

40. Lee SY, Yang DH, Hwang E, et al. The prevalence, association, and clinical outcomes of frailty in maintenance dialysis patients. J Ren Nutr 2017;27:106-12.

41. Collins AJ, Foley RN, Chavers B, et al. US Renal Data System 2013 Annual Data Report. Am J Kidney Dis 2014;63(1 Suppl):A7.

42. Kim JC, Kalantar-Zadeh K, Kopple JD. Frailty and protein-energy wasting in elderly patients with end stage kidney disease. J Am Soc Nephrol 2013;24:337-51.

43. Stenvinkel P, Larsson TE. Chronic kidney disease: a clinical model of premature aging. Am J Kidney Dis 2013;62:339-51.

44. Walker SR, Wagner M, Tangri N, et al. frailty, and unsuccessful aging: a review. J Ren Nutr 2014;24:364-70.
45. McAdams-DeMarco MA, Law A, Salter ML, et al. Frailty as a novel predictor of mortality and hospitalization in individuals of all ages undergoing hemodialysis. J Am Geriatr Soc 2013;61:896-901.

46. Sood MM, Rigatto C, Bueti J, et al. The role of functional status in discharge to assisted care facilities and in-hospital death among dialysis patients. Am J Kidney Dis 2011;58:804-12.

47. Brown EA, Johansson L. Old age and frailty in the dialysis population. J Nephrol 2010;23:502-7.

48. Johansen KL, Delgado C, Bao Y, et al. Frailty and dialysis initiation. Semin Dial 2013;26:690-6.

49. de Labra C, Guimaraes-Pinheiro C, Maseda A, et al. Effects of physical exercise interventions in frail older adults: a systematic review of randomized controlled trials. BMC Geriatr 2015;15:154.

50. Matsuzawa R, Hoshi K, Yoneki K, et al. Exercise training in elderly people undergoing hemodialysis: a systematic review and metaanalysis. Kidney Int Rep 2017;2:1096-110.

51. Chan D, Cheema BS. Progressive resistance training in end-stage renal disease: systematic review. Am J Nephrol 2016;44:32-45.

52. Headley S, Germain M, Mailloux P, et al. Resistance training improves strength and functional measures in patients with end-stage renal disease. Am J Kidney Dis 2002;40:355-64.

53. Chandler JM, Duncan PW, Kochersberger G, et al. Is lower extremity strength gain associated with improvement in physical performance and disability in frail, community-dwelling elders? Arch Phys Med Rehabil 1998;79:24-30.

54. Morishita S, Tsubaki A, Shirai N. Physical function was related to mortality in patients with chronic kidney disease and dialysis. Hemodial Int 2017;21:483-9. 